\title{
Social And Health Related Effects of Smart Phone Usage Among University Students
}

Junaid Tariq, Ambreen Usmani, Maroosha Imran, Naveed Faraz

\begin{abstract}
:
Objective: To assess the social and health related effects of smart phone usage among the students of a public university in Karachi.
\end{abstract}

Study Design and Setting: Cross sectional study conducted on students of a public university of Karachi from July 2018 to October 2018

Methodology: A research questionnaire was distributed among students of a public university in Karachi. This anonymous questionnaire addressed the perceptions of the university students regarding usage of smart phones and its effects on health and social life. A total of 150 students were included in the study. The variable checked were effects on eyesight, whether the students feel relaxed or suffered from depression, experiences of headache, the effect on the students' studies and family issues. Data was entered in SPSS version 23 and frequencies were calculated. Chi-square was applied on each variable and $\mathrm{p}$-value less than 0.05 was considered significant.

Result: One hundred and fifty students participated, of which 75 were females and 75 were males. It was observed those females were using WhatsApp more than their male counterparts. Males showed a slightly higher frequency of using Facebook and other internet Apps. From the total sample 66.6\% noticed decrease in their eye sight, $17 \%$ are depressed, $38 \%$ had headache, $42 \%$ had bad effects on their studies and $43 \%$ had family related issues due to usage of smart phone

Conclusion: Use of smart phone has many adverse effects on university students like poor eye sight, depression, headaches, effects on studies and family issues.

Key words: Impact, depression, smart phone, university students.

\section{INTRODUCTION:}

Mobile phones are becoming increasingly ubiquitous. In the beginning it was used as a communication tool, however with time the innovation and growth of the mobile phones is astonishing and used for web browsing, social networking, watches, alarms clocks, games, camera, and calculator etc. ${ }^{1}$ Smart phones are modern gadget and popular in all ages. The use of smart phones among young children and students has increased dramatically. Although it has some advantages however, concerns have been raised about the adverse health impacts associated with their use. One of the most widely expressed concerns is the radiofrequency $(\mathrm{RF})$ waves emitted

Г- - - - - - - - - - - - -

Junaid Tariq

I College of Physicians and Surgeons

Karachi

Ambreen Usmani

Professor, HOD - Anatomy,

DD-Medical Education

Vice Principal Medical College

Bahria University Medical and Dental College

I Karachi

I

Maroosha Imran

MBBS student

I Ziauddin University, Karachi

I Naveed Faraz

I Professor, Department of Pathology

Bahria University Medical and Dental College

I Karachi

Received: 06-02-2019

I Accepted: 17-05-2019 during use which may lead to an increase in brain cancer risk. ${ }^{2}$ Excessive use of mobile phones may cause psychological illness such as dry eyes, computer vision syndrome, weakness of thumb and wrist, neck pain and rigidity, increased frequency of De Quervain's tenosynovitis, tactile hallucinations, nomophobia, insecurity, delusions, auditory sleep disturbances, insomnia, hallucinations, lower self-confidence, and mobile phone addiction disorders. ${ }^{3}$

According to the latest studies, increase dependence on mobile phones may lead to an increase internet addiction. ${ }^{4}$ Research has proved that smart phone is a source of the eminence of electromagnetic waves. Several studies have been conducted in the last decades to identify the effect of electromagnetic waves emitted from the cell phones on human health. The impact of harmful radiation emitted from cell phones waves is still being studied. ${ }^{5}$ According to literature; male users spend less time as compared to female like many other studies. ${ }^{6,8}$ There are many ill effects on health due to the utility of smart phone as on the eye sight. ${ }^{9}$ Some researchers have pointed out that these gadgets have effect on the studies excessively and results in academic decline due to more time spend on gadgets. ${ }^{10}$ It is also observed that family relation were also affected due to lack of conversation with their family members. Studies revealed that children have started to feel emotionally unsatisfied as parents are becoming equally dependent and addicted to smart phones. ${ }^{11}$ Studies have shown that how adolescents experience domestic violence especially with those who have a higher likelihood of smart phone addiction. 
Furthermore, higher levels of self-control and peer relationship satisfaction has been shown when there is decrease utility of smart phone addiction. ${ }^{12}$ There is the potential effect of smart phone addiction on family stress and increasing depression. ${ }^{13,14}$ Excessive usage can lead to depression and further suicide tendency, a study showed that $17 \%$ of the students claimed to feel depressed, whereas other studies predict that more than $60 \%$ of the teenage population by the end of 2020 would show symptoms of depression. ${ }^{15,16,17}$

The aim of this study was to assess the social and health effects of smart phone among the students of a public university of Karachi such as effects on eye sight, headache, depression, studies related and family related problems.

\section{METHODOLOGY:}

This study was performed by convenient sampling for a period of three months from July to October 2018. This anonymous questionnaire addressed the perceptions of the university students regarding usage of smart phones and their impact on health and social life. A total of 150 students were included in the study. Multiple questions were asked related to the eye sight, depression, headache, effect on studies and family related issues. The data was entered and

Graph 1: Gender differences in using social websites

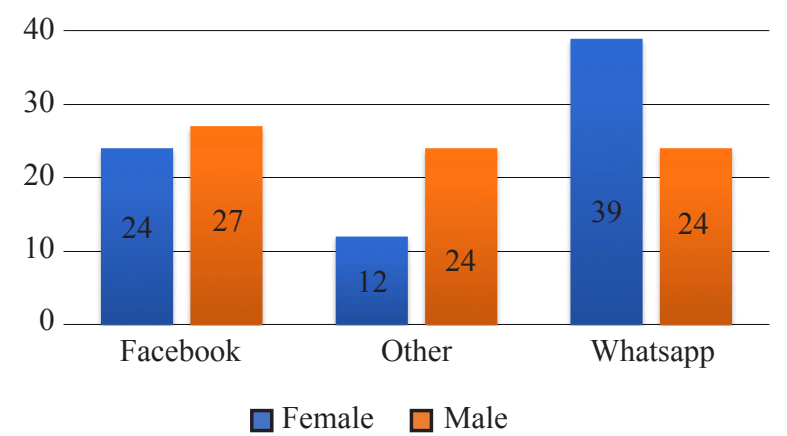

analysed by SPSS version 23.Chi-square was applied on each categorical variable and $p$-value less than 0.05 was considered significant.

\section{RESULTS:}

One hundred and fifty students participated, of which 75 were females and 75 were males. Overall perception was that female was using WhatsApp more than their male counterparts. Males showed a slightly higher frequency of using facebook and other internet Apps. (Graph-I).It was observed that eye sight was markedly affected as $66.6 \%$ showed negative impact on eye sight. 50\% of people showed no effect on their psychological behavior after they were using smart phone. It was observed that $44 \%$ of sample expressed no headache after using smart phone while $38 \%$ were suffering from headache. $58 \%$ has no effect on their studies as compare to $42 \%$ who have effect on their studies if they were using smart phone. It was observed that people who were more involved in using smartphone their relation with their family members were less emotional as $57 \%$ of sample has unsatisfied family relation as compare to $43 \%$ who have good relation with family members. (Table- 1).

\section{DISCUSSION:}

Technological advancements in mobile phone industry have changed the way we interact with our peers. This study was done to observe the impact of using smart phone over health. It was observed in the study that male users spend less time as compared to female like many other studies. ${ }^{6,7,8} \mathrm{We}$ observed that the eye sight of those who were using smart phone was markedly affected with a decrease in eye sight, which was similar with another previous. ${ }^{9}$ Headache is prevalent in smart phone user, this was also reflected in our study. Due to wastage of time some researchers have pointed out that these gadgets have effect on the studies who use

Table 1: Adverse effects of Smart Phone on Health

\begin{tabular}{|l|l|l|l|l|l|}
\hline \multicolumn{2}{|c|}{ Variables } & Male & Female & Total & P-value \\
\hline \multirow{3}{*}{ Eye sight effect } & Yes & $51(34 \%)$ & $49(32.6 \%)$ & $100(66.6 \%)$ & \multirow{3}{*}{0.017} \\
\cline { 2 - 5 } & No & $13(8.6 \%)$ & $18(12 \%)$ & $31(20.6 \%)$ & \\
\cline { 2 - 5 } & Don't Know & $11(7.3 \%)$ & $8(5.3 \%)$ & $19(12.6 \%)$ & \\
\hline \multirow{3}{*}{ Feel like } & Relaxed & $23(15 \%)$ & $26(18 \%)$ & $49(33 \%)$ & \multirow{2}{*}{0.039} \\
\cline { 2 - 5 } & Depressed & $14(9 \%)$ & $12(8 \%)$ & $26(17 \%)$ & \\
\cline { 2 - 5 } & No Effect & $38(25 \%)$ & $37(25 \%)$ & $75(50 \%)$ & \multirow{2}{*}{0.015} \\
\hline \multirow{2}{*}{ Effect on Studies } & Yes & $20(13 \%)$ & $37(25 \%)$ & $57(38 \%)$ & \multirow{2}{*}{0.006} \\
\cline { 2 - 5 } & No & $40(27 \%)$ & $26(17 \%)$ & $66(44 \%)$ & \\
\cline { 2 - 5 } & Don't Know & $15(10 \%)$ & $12(8 \%)$ & $27(18 \%)$ & \\
\cline { 2 - 5 } & No & $26(17 \%)$ & $37(25 \%)$ & $63(42 \%)$ & \\
\hline \multirow{2}{*}{ Family Issues } & Family satisfied & $31(21 \%)$ & $33(22 \%)$ & $64(43 \%)$ & \multirow{2}{*}{0.007} \\
\cline { 2 - 5 } & Family unsatisfied & $44(29 \%)$ & $42(28 \%)$ & $86(57 \%)$ & \\
\hline
\end{tabular}


smart phones excessively which result in academic decline, this was highlighted in our study. ${ }^{10}$ It was also observed that people involved in using smart phone their family relation tend to be affected due to lack of conversation with their family members. Studies show that children have started to feel emotionally unsatisfied as parents are becoming equally dependent and addicted to smart phones. ${ }^{11}$ Studies have shown that adolescents experience domestic violence due to addiction of smart phone. Furthermore, higher levels of self-control and peer relationship satisfaction has been shown when there is less addiction of smart phone. ${ }^{12}$ Although the results of this study need to be further clarified and validated by further studies, our study provides evidence regarding the potential health effects due to smart phone addiction like other studies. ${ }^{13,14}$ Excessive usage can lead to depression and further suicide tendency, a study showed $17 \%$ of the students claimed to feel depressed, whereas another studies predict that more than $60 \%$ of the teenage population by the end of 2020 will show signs and symptoms of depression. ${ }^{15,16,17}$

With widespread use of the smart phone, clinical evidence for smart phone addiction remains unclear. Against this background, a study analysed the effect of smart phone use patterns on smartphone addiction in Korean adolescents. A total of 370 middle school students participated and severity of smartphone addiction was measured through clinical interviews and the Korean Smartphone Addiction Proneness Scale. As a result, $50(13.5 \%)$ were in the smartphone addiction group and $320(86.5 \%)$ were in the healthy group. For smartphone functions mostly used, the addiction group showed significantly higher scores in online chating. ${ }^{18}$ For problematic use, the addiction group showed significantly higher scores on pre-occupation, tolerance, lack of control, withdrawal, mood modification, conflict, lies, excessive use and loss of interest. ${ }^{19}$ In our study the effects of being addicted and resulting in headache was shown in $38 \%$ students which was comparable with is various literaturure. ${ }^{11,20}$

Excessive use of smart phone causes adverse effects on studies as more time is spent on internet surfing. Making virtual friends has become more popular rather than real friends. In our study $63 \%$ said that their academic studies have been adversely affected as evidenced in ample literature. .,, $2015^{2}$. Total $57 \%$ students commented that they suffer from family issues including feeling of depression and being deprived of a lot of luxury when they see photos of others who pose artificial happy photos and selfies which itself has converted into a syndrome. ${ }^{5}$ To keep up with the time changes smart classrooms are being used in affluent colleges, again leaving the less privileged deprived which results in family pressure and issues but it must be understood that social media is only an adjunct and not a replacement of classroom teaching. ${ }^{21}$

The use of mobile technologies is a promptly growing field which includes various specialities. Audio-visual communication via smartphones is a new introduction that has spread enormously throughout the world and gaining more popularity by including attractive apps. A nationwide survey performed in the United States in 2011 included 3306 medical providers and found that more than half used various apps in their clinical practice, some of which had not been specifically developed for medical purposes. ${ }^{1,79}$

WhatsApp Messenger is one of the most popular mobile apps, ${ }^{22}$ its usage is becoming more popular as a social site as well as a forum for studies exchange of notes and knowledge sharing in the form of articles and e-books. The requirement of only a mobile internet connection explains the app's widespread success. ${ }^{23,24}$

Increasing use of social media by our present generation of students has its own pros and cons. However, if used in the right way, social media might be deployed to complement medical education." There are certain peculiarities of social media which make it an ideal platform for teaching. It connects a large number of people at the same time. The participants have freedom of choosing a time when they want to access the information posted. "A single topic of discussion or a single case can be discussed over 1 or 2 days at leisure, which makes the exercise more interesting. The indiscriminate sharing of data on mobiles, particularly on group chats, raises further challenges. The usage of skype including other video sharingprocedures has allowed lectures by eminent scholars to be delivered to students of different countries which allows sharing of recent knowledge and keeping scholars up to date. ${ }^{15,19,21}$

\section{CONCLUSION:}

It was included in this study that use of smart phone has many social and health effects on university students like poor eye sight, depression, headaches, effects on their studies and family issues.

\section{REFERENCES:}

1. Balakrishnan V, Raj RG. Exploring the relationship between urbanized Malaysian youth and their mobile phones: a quantitative approach. Telemat Inform. 2012;29(3):263-72

2. Repacholi MH. Health risks from the use of mobile phones. Toxicol Lett. 2001;120:323-31

3. Peraman R, Parasuraman S. Mobile phone mania: Arising global threat in public health. J Nat Sci Biol Med. 2016;7:198-200.

4. Billieux JL, van der Linden M, Rochat L. The role of impulsivity in actual and problematic use of the mobile phone. Appl Cogn Psychol. 2008;22:1195-210.

5. Jeong HS, Lee YS. Smartphone addiction and empathy among nursing students. Adv Sci Technol Lett. 2015;88:224-8.

6. Alim-Marvasti A, Bi W, Mahroo OA, et al.Transient smartphone blindness: Precaution Needed. N Engl J Med 2016;374:2502-2504.,

7. Sathiamoorthi S, Wingerchuk DM. Transient smartphone blindness: relevance to misdiagnosis in neurologic practice. Neurology. 2017;88(8):809-810. 
8. Irshad F, Adhiyaman V. Can J Ophthalmol.Transient smartphone blindness. 2017;52:107-108. doi: [10.7759/cureus. 1796]

9. Kim K. Association between Internet overuse and aggression in Korean adolescents. Pediatrics international. 2013;55(6):703-9.

10. Enez Darcin A, Kose S, Noyan CO, Nurmedov S, Yýlmaz O, Dilbaz N. Smartphone addiction and its relationship with social anxiety and loneliness. Behaviour \& Information Technology. 2016;35(7):520-5.,

11. Baek HW, Shin YM, Shin KM. Emotional and Behavioral Problems Related to Smartphone Overuse in Elementary School Children. Journal of Korean Neuropsychiatric Association. 2014;53(5):320-6.

12. Hwang K-h, Yoo Y-s, Cho O-h. Smartphone overuse and upper extremity pain, anxiety, depression, and interpersonal relationships among college students. The Journal of the Korea Contents Association. 2012;12(10):365-75.

13. Kee I-K, Byun J-S, Jung J-K, Choi J-K. The presence of altered craniocervical posture and mobility in smartphoneaddicted teenagers with temporomandibular disorders. Journal of physical therapy science. 2016;28(2):339

14. Giordano V, Koch H, Godoy-Santos A, Belangero WD, Pires RES, Labronici P. WhatsApp Messenger as an Adjunctive Tool for Telemedicine: An Overview. Interactive Journal of Medical Research Interact J Med Res 2017;6(2): e11.doi: 10.2196/ijmr.6214.

15. Vásquez-Silva L, Ticse R, Alfaro-Carballido L, GuerraCastañon F, authors. [Access, use and preferences of information and communication technologies by physicians in a general hospital in Peru]. Rev Peru Med Exp Salud Publica 2015;32(2):289-93
16. Clark PA, Capuzzi K, Harrison J, authors. Telemedicine: medical, legal and ethical perspectives. Med Sci Monit. 2010 ;16(12):RA261-72. [Medline: 21119593]

17. Bal AM. Whatsap Doc, Indian Journal of Medical Ethics 2017;2(1):65 DOI: 10.20529/IJME.2017.016

18. Gulacti U, Lok U, Çelik M. Use of WhatsApp application for orthopedic consultations in the ED. Am J Emerg Med. 2016;34(7):1305-7. doi: 10.1016/j.ajem.2016.04.004.?

19. Drake TM, Claireaux HA, Khatri C, Chapman SJ. WhatsApp with patient data transmitted via instant messaging?Am J Surg 2016;211(1):300-1. doi: 10.1016/j.amjsurg.2015.04.004.?

20. Sumitra G. Bakshi and Pranay Bhawalkar. Role of WhatsAppbased discussions in improving residents' knowledge of postoperative pain management: a pilot study. Korean $\mathrm{J}$ of Anaesthesiol. 2017;70(5):542-549

21. Meissner W, Coluzzi F, Fletcher D, Huygen F, Morlion B, Neugebauer E, et al. Improving the management of postoperative acute pain: priorities for change. Curr Med Res Opin 2015; 31: 2131-43

22. Drake TM, Claireaux HA, Khatri C, Chapman SJ. WhatsApp with patient data transmitted via instant messaging?Am J Surg. 2016;211(1):300-1. doi: 10.1016/j.amjsurg.2015.04.004.?

23. Lee H, Kim JW, Choi TY.J Korean Med Sci. Risk Factor for Smartphone Addiction in Korean Adolescents: Smartphone Use Patterns. 2017;32(10):1674-1679. doi: 10.3346/jkms. 2017.32.10.1674.

24. Naeem $Z$. Health risks associated with mobile phones use. Int J Health Sci (Qassim). 2014;8(4):5-6. 